\title{
Influence of air temperature on children water contacts with respect to schistosomiasis transmission risk in the Sourou Valley, Burkina Faso
}

\author{
Issouf Traore $^{1,3} \cdot$ Daniel Karthe $^{2,3} \cdot$ Ali Sie $^{1} \cdot$ Victor Coulibaly $^{1} \cdot$ Martin Kappas $^{3}$
}

Published online: 23 January 2016

(c) The Author(s) 2016. This article is published with open access at Springerlink.com

\begin{abstract}
Climate and water contacts are among the most important risk factors of human schistosomiasis transmission. This study aimed to determine-through direct field observations - the influence of air temperature on the frequencies of childreńs water contacts with respect to human schistosomiasis transmission risk in the Sourou Valley, located in the North-western part of Burkina Faso. The objectives of the study were: (i) to study the air temperature at which children have the sensation of heat and start looking for water as a means for natural cooling; and (ii) to study whether high frequencies of swimming or bathing may lead to a higher risks of schistosomiasis transmission. To do so, swimming or bathing were observed during two different periods: a cold one from 3rd January to 2nd February 2011 and a hot one from 3rd April to 3rd May 2011 in Toma-Île, a village totally surrounded by water. The results showed that daily mean air temperatures never exceeded $30{ }^{\circ} \mathrm{C}$ during the coldest period, while they were above this value during the hottest period. In total, swimming activities were observed 11/31 days during the coldest period and 31/31 during the hottest period. Bathing of children below the age of 5 years occurred on $55 / 62$ days. $25{ }^{\circ} \mathrm{C}$ was the day mean air temperature from which children felt hot and began playing in water. The hourly occurrence of swimming and bathing showed peaks
\end{abstract}

Issouf Traore

t_issouf2000@yahoo.fr

1 Centre de Recherche en Santé de Nouna, BP 02, Nouna, Burkina Faso

2 Helmholtz Centre for Environmental Research, Magdeburg, Germany

3 Department of Geography, Georg-August Universität, Göttingen, Germany at 2 PM. This coincides with the diurnal maximum of infective cercariae present in the same water. Thus, in order to freshen up during hot periods of the day, children used to look for freshwater and thus expose themselves to a high schistosomiasis transmission risk.

Keywords Air temperature - Water contacts - Human schistosomiasis · Children · Sourou valley $\cdot$ Burkina Faso

\section{Introduction}

Human schistosomiasis (also known as Bilharzia) is a disease caused by infection with blood flukes of the Schistosoma genus. Most cases of the disease result from infection with Schistosoma japonicum and S. mansoni, both of which cause intestinal schistosomiasis and S. haematobium, the causative agent of urinary schistosomiasis. The larvae of the organism (cercariae) are released into water by infected snail as intermediate hosts. Human contact with water inhabited by snails is the source of the persistence of the transmission of schistosomiasis (WHO 2013). As a water-based disease, schistosomiasis comes second only to malaria in terms of public health impact. Globally, there are approximately 779 million persons at risk and 207 million persons infested (Van der Werf et al. 2003; Gryseels et al. 2006; Steinmann et al. 2006; Utzinger et al. 2009; WHO 2013). Higher prevalence and intensity of infections are concentrated in childhood (Butterworth and Hagan 1987; Fulford et al. 1998; Kabatereine et al. 1999). In the case of urinary schistosomiasis, the eggs cause damage to the urinary tract and blood appears in urine (haematuria). Urination becomes painful and there is progressive damage to the bladder, ureters and kidneys. Bladder cancer is a common complication (van der Werf 
et al. 2003; Gryseels et al. 2006; Steinmann et al. 2006; Utzinger et al. 2009; WHO 2013). In the case of intestinal schistosomiasis, the eggs bring about progressive enlargement of the liver and spleen as well as damage to the intestine and hypertension of the abdominal blood vessels. Symptoms such as bloody diarrhoea, abdominal pains and fatigue are commonly reported (Gryseels and Nkulikyinka 1990). A very significant proportion of death due to schistosomiasis is concentrated in Sub-Saharan Africa (SSA). There are approximately 150,000 cases of death from urinary schistosomiasis and 130,000 from S. mansoni infections in SSA, per annum (van der Werf et al. 2003; King and Dangerfield-Cha 2008; Hotez and Kamath 2009).

Climate, environment and human behaviour remain the most important risk factors of human schistosomiasis transmission (Weil and Kvale 1985; Mayer 1983; Ernould 2000; Scott et al. 2003; Gazzinelli et al. 2006; Mangal et al. 2008; Zhou et al. 2008; Koukounari et al. 2011; Tay et al. 2011). Much is known about the influence of temperatures on parasites and intermediate hosts through numbers of studies by biologists. Water temperatures between 10 and $30{ }^{\circ} \mathrm{C}$ are a prerequisite for egg hatching. The ability of the hatching miracidia (the first development stage of the parasite) to penetrate snails is also influenced by water temperature with an optimum occurring between 26 and $28{ }^{\circ} \mathrm{C}$. Below $10^{\circ} \mathrm{C}$, miracidia are very inactive (DeWitt 1955; Chu et al. 1966). The parasites within the snail intermediate host are profoundly influenced by habitat temperatures, particularly the duration of the pre-patent period in snails (Stirewalt 1954; DeWitt 1955). Similar results were obtained with the Egyptian $S$. mansoni in Planorbis pfeifleri, where the pre-patent period lasted 15 days at $32-33{ }^{\circ} \mathrm{C}$; $19-22$ days at $26-28{ }^{\circ} \mathrm{C}$; and 33-37 days at $20-22{ }^{\circ} \mathrm{C}$. Comparable periods for $S$. haematobium in Physopsis globosa were 22-23 days at $32-33{ }^{\circ} \mathrm{C}$; 36 days at $26-28{ }^{\circ} \mathrm{C}$ and $66-68$ days at $20-22{ }^{\circ} \mathrm{C}$. The infectivity rate or the cercariae capacity to penetrate the skin depends on temperature with an optimum ranging from 26 to $28{ }^{\circ} \mathrm{C}$ (Stirewalt 1954).

Human behaviour plays a key role in the schistosomiasis transmission process. Through various water contacts, the human being ensures the success of the circulation of parasites (Weil and Kvale 1985; Chandiwana 1987; Takougang et al. 1993; Amazigo et al. 1997; Kloos et al. 1998; Watts et al. 1998; Ernould 2000; Scott et al. 2003; Grisorio et al. 2005; Gazzinelli et al. 2006). Various studies addressed the role of different water contact activities and relevant age groups but their results vary with regard to the incidence or prevalence of schistosomiasis infections. In Sub-Saharan Africa, the most important water contact activity in childhood is swimming or bathing, the frequencies of which depend on the variability of air temperature. Understanding the short and mid-term influence of air temperature on children exposure to contaminated water may help develop innovative strategies towards effective control of schistosomiasis. To date, such information is not available.

This study tested the short-term (hourly) and the midterm (diurnal scale) influence of air temperature on the frequencies of children's water contacts with respect to human schistosomiasis transmission risk. The objectives of the study were the following: (i) to study the air temperature at which children have the sensation of heat and start looking for water as a means for natural cooling; and (ii) to study whether daily and hourly occurrence of swimming or bathing leads to higher risks of human transmission of schistosomiasis.

\section{Materials and methods}

\subsection{Study site}

This direct field observation was conducted in Toma-Île $\left(\mathrm{N} 13^{\circ} 08.807^{\prime}, \mathrm{W} 3^{\circ} 27.056^{\prime}\right)$, a village totally surrounded by water throughout the year, in the Sourou Valley, in the Northwestern part of Burkina Faso. The Sourou River is surrounded by a large scale irrigation scheme that is typical in size and character for similar developments in Sub-Saharan Africa. Since the construction of a dam in 1976, water flow in the river is regulated and the river is de facto turned into a reservoir storing up to 200 million cubic meters of water (Karthe et al. 2011). The Sourou River marks the boundary between the provinces of Kossi and Sourou (the umbrella province of Toma-Île). The region is characterized by a semiarid tropical climate, difficult access even to basic health infrastructure and high prevalence of water associated diseases, the most relevant which are malaria and schistosomiasis (Karthe and Traoré 2009; Karthe 2010; Traoré et al. 2011; Karthe et al. 2012; Traoré et al. 2012; Traoré 2013). A canoe is always needed to access Toma-Île. The Sourou River, a perennial one, is the main water source for the community. Safe water supply and wastewater treatment facilities were non-existent during the study period (2011). The absence of trees on the island suggests that the most common way to freshen up during the intense midday heat is bathing or swimming in the river. Previous epidemiologic and biologist studies showed that human schistosomiasis is widely spread in Burkina Faso (Poda et al. 2004; Koukounari et al. 2007; Clements et al. 2008; Koukounari et al. 2011; Zongo et al. 2012). Snails intermediate hosts collected and identified in the Sourou Valley were: Biomphalaria pfeifferi for the intestinal schistosomiasis (S. mansoni) and Bulinus truncatus and $B$. senegalensis for the urinary schistosomiasis $(S$. haematobium) (Dianou et al. 2004; Poda et al. 2004; Zongo et al. 2012). The levels of prevalence in Toma-Île village were 
$51.9 \%$ for the urinary schistosomiasis and $50.6 \%$ for the intestinal schistosomiasis among school aged children. Two years after in 2002 prevalence were 43.4 and $90.8 \%$, respectively (Poda et al. 2004). Zongo et al. (2012) indicated a global prevalence of $3 \%$ for S. haematobium among school aged children in the Sourou Valley and within a particular context of mass drug administration with praziquantel. These authors have also observed that in general in Burkina Faso, prevalence of $S$. haematobium is decreasing while that for $S$. mansoni is increasing. Schistosomiasis remains a major public health problem in endemic settings to both $S$. haematobium and S. mansoni like Toma-Île in the Sourou Valley.

\subsection{Observation periods}

For comparison purpose, both hot and cold periods of 1 month (31 days) were selected. In order to identify these two periods, we used a 31-year monthly mean air temperature dataset obtained from the Di-Sourou weather station (located $4 \mathrm{~km}$ from Toma-Île). We determined that for an average year (Fig. 1), the coldest period runs from 3rd January to 2nd February (31 days) and the hottest period from 3rd April to 3rd May 2011 (31 days). During these two observation timeframes, we recorded all activities affecting a partial or total immersion into water. Daily observations were carried out from $6 \mathrm{AM}$ to $6 \mathrm{PM}$ (12 h/day).

The study schedule, the data collection method and two fieldworkers supporting the observation were introduced to the community through an informative meeting held in December 2010. The community members in general specifically women were made aware of the study by its supervisor and a delegated administrative representative.

\subsection{Activities tracked and determination of children's ages}

Two water contact activities were of concern: recreational swimming and bathing. Children were the target population.

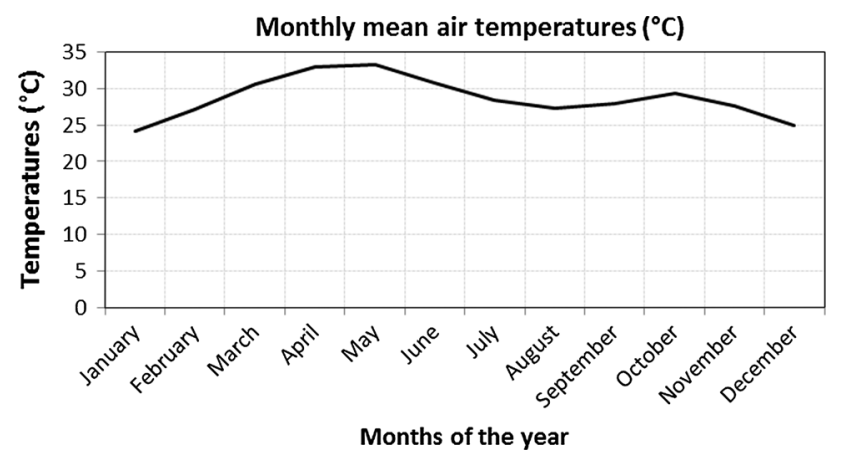

Fig. 1 A 31-year (1980-2010) curve of mean air temperatures (data from Di-Sourou weather station)
In the context of the paper, swimming refers to a recreational water activity carried out by children aged between 5 and 14 years, typically consisting in a total immersion of the body (Chandiwana 1987; Takougang et al. 1993). Conversely, bathing refers to children below the age of 5 years being brought to and washed by their mothers or other persons into the river. Children were not followed up individually. Fieldworkers were asked to report daily entries into contact with water. A child or a woman can have several such contacts per day. Only the hourly water contact frequencies at the observed sites were recorded in the day.

To determine the age of children, fieldworkers asked directly to children and requested confirmation from their parents. To identify children less than 5 years, any children seen with their parents in the river were asked about their ages and confirmations were given by the mothers, if any. Since the fieldworkers were from the local community it was easy to estimate the ages of children.

\subsection{Identification of the mean air temperature threshold}

This threshold separates air temperature conditions where a water-contact is likely to be observed versus those where it is likely to be absent. We used a simplest method of breakpoint-based threshold which consists of visually estimating the location of the threshold from plotted data (Ficetola and Denoël 2009). In the presence study, the identification of the breakpoint-based threshold was easy because no swimming occurred over the first 20 days of the direct field observations. Swimming was observed over the rest of 42 days of direct observation. Therefore, the threshold was located at the 21 st day of observation. Using a graph, we plotted the 62 days of observation on the $\mathrm{X}$ axis and the corresponding mean air temperatures on the $\mathrm{Y}$ axis. Then we projected the 21st day on the $\mathrm{Y}$ axis to determine the mean air temperature as the threshold.

\section{Results}

\subsection{Overall outcomes of recording}

\subsubsection{Temperatures variability during the direct observation period}

Figure 2a shows minimal air temperatures daily profile for both coldest and hottest periods. The extremes varied between 11.5 and $19.8^{\circ} \mathrm{C}$ (range $8.3^{\circ} \mathrm{C}$ ), and 20.0 and $30.5^{\circ} \mathrm{C}$ (range $10.5^{\circ} \mathrm{C}$ ), respectively. Figure $2 \mathrm{c}$ compares daily maximal air temperatures of the coldest and hottest periods. Extreme values varied between 29.0 and $40.3{ }^{\circ} \mathrm{C}$ (range $11.3^{\circ} \mathrm{C}$ ), and 35.5 and $45.0^{\circ} \mathrm{C}$ (range $9.5^{\circ} \mathrm{C}$ ), 
(a)

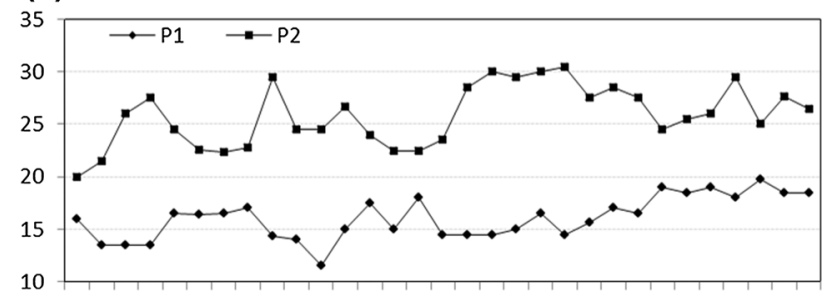

(b)

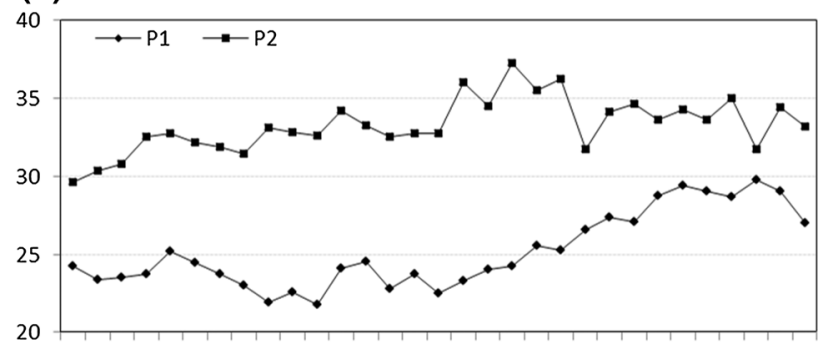

(c)

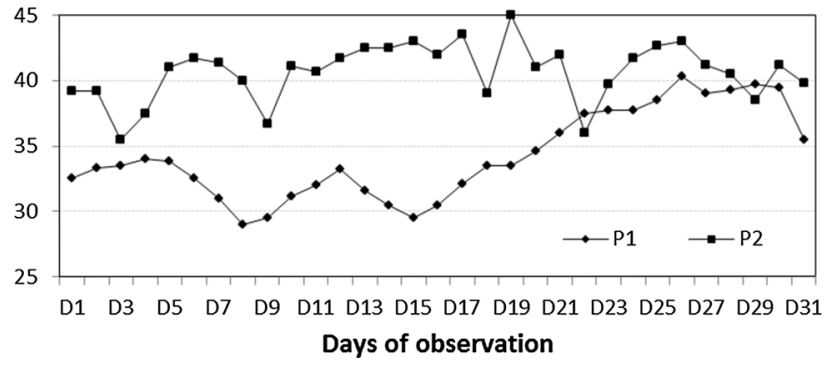

Fig. 2 Profiles of air temperatures during the periods of observations (Data from Di-Sourou weather station). a Minima, b Mean, c Maxima; P1 coldest period (D1 3rd January, D31 2nd February 2011); P2 hottest period (D1 3rd April, D31 3rd May 2011)

respectively. Means of minima and maxima per period are plotted in Fig. 2b. Daily mean air temperatures never exceeded $30.0{ }^{\circ} \mathrm{C}$ during the coldest period, as opposed to the hottest period where they exceeded this value. Mean temperatures on the coldest day of the hot period exceeded those of the hottest day of the cold period. The same applies to minimum temperatures and, with minor exceptions, to the daily maxima (Fig. 2).

\subsubsection{Water contact frequencies during the period of direct observation}

Figure 3a shows that swimming was observed during $11 / 31$ days and extreme numbers of water contacts varied between 0 and 42 (average of 9.3 contacts/day, $95 \%$ CI 7.5-11.1) during the coldest period. By contrast, during the hottest period swimming occurred during 31/31 days, with extreme numbers ranging from 18 to 192 (average of 77.6 contacts/day, $95 \%$ CI 73.1-82.0). Over the entire observation period, swimming activities were observed during $42 / 62$ days. This means that there were 20 days without recreational swimming.
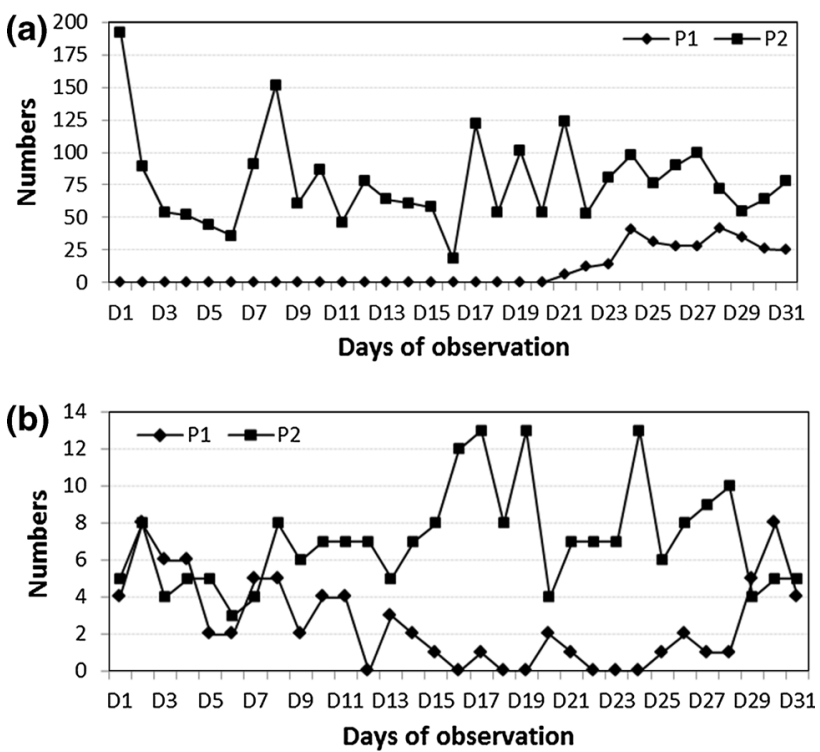

Fig. 3 Water-contact frequencies. a Frequencies of swimming, b Frequencies of bathing of children less than 5 years. $P 1$ Coldest period (D1 3rd January, D31 2nd February 2011); P2 hottest period (D1 3rd April, D31 3rd May 2011)

Figure $3 \mathrm{~b}$ shows the daily water contacts through bathing of children less than 5 years directly in the river by their mothers. During the coldest period this activity was observed during 24/31 days and extreme numbers of contacts varied between 0 and 8 (average of 3.0 contacts/day, $95 \%$ CI 2.7-3.3). Similarly to swimming, bathing was recorded all 31/31 days with extreme numbers ranging from 3 to 13 contacts (average of 7.0 contacts/day, $95 \% \mathrm{CI}$ 6.6-7.4). Over of the entire observation period, bathing occurred during 55/62 days. Therefore, there were 7 days without any contact with the river.

\subsection{Influence of air temperatures on water-contact frequencies}

\subsubsection{Mean term influence (day scale)}

Figure 4 shows results of the influence of air temperature on children recreational swimming in the river. Graphs a1, $\mathrm{b} 1$ and $\mathrm{c} 1$ show the patterns of the coldest period; graphs $\mathrm{a} 2$, b2, and c2 show the patterns of the hottest period. Results show that swimming never occurred on the days where the minimal air temperature was less than $15^{\circ} \mathrm{C}$. The first cases of swimming were observed on days where the maximal air temperature reached $35^{\circ} \mathrm{C}$, typically coinciding with mean daily air temperatures of more than $25{ }^{\circ} \mathrm{C}$. The values of the coefficients of determination $\left(\mathrm{R}^{2}\right)$ for the coldest period were higher than those for the hottest period. 
Fig. 4 Plot of daily air temperatures and frequencies of recreational swimming. Graphs $a 1, b 1, c 1$ show the situations of the coldest period; and graphs $a 2, b 2, c 2$ indicate the situations of the hottest period (a1)

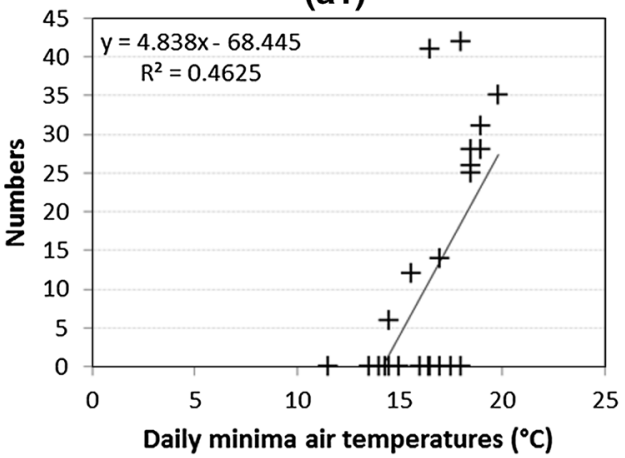

(b1)

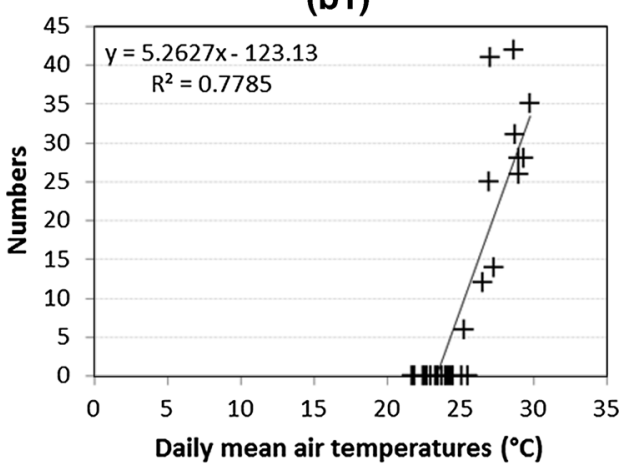

(c1)

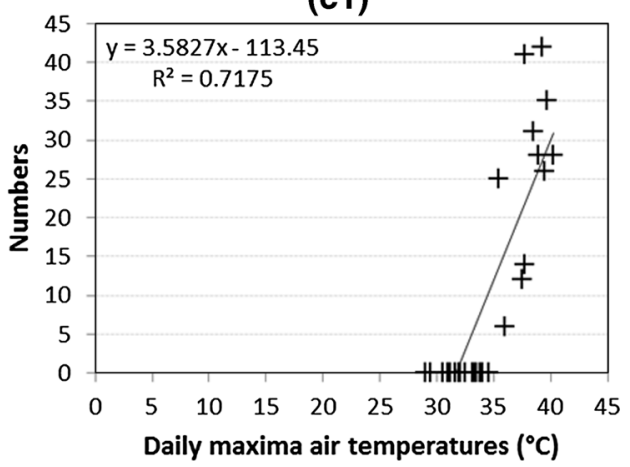

(a2)

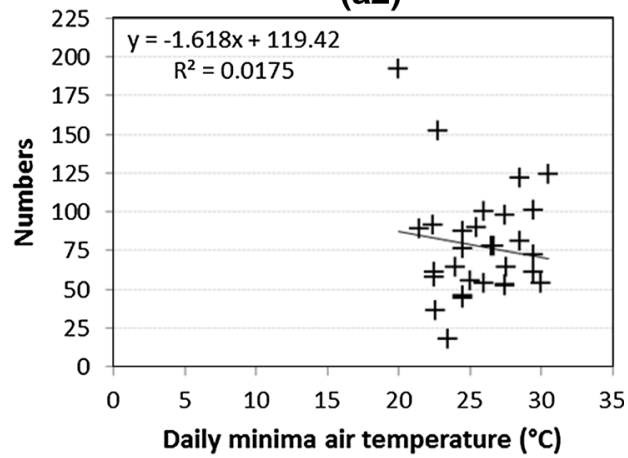

(b2)

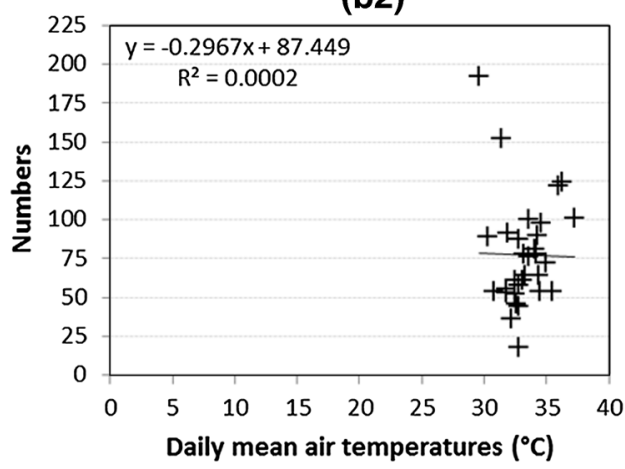

(c2)

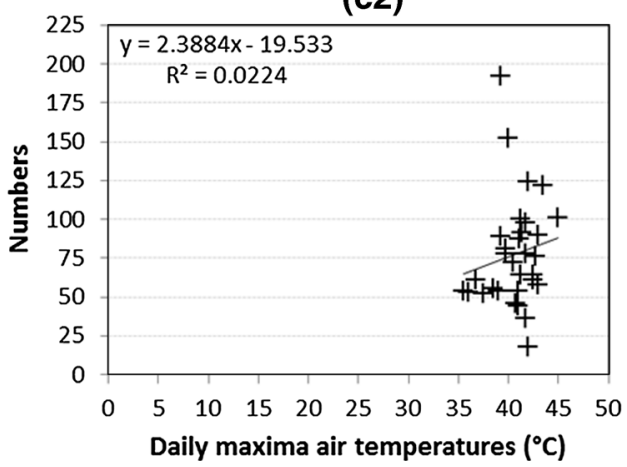

Figure 5 displays the results of the influence of air temperature on frequencies of bathing children less than 5 years directly in the river. Graphs a1, b1 and 1 show the patterns of the coldest period; graphs a2, b2, and c2 show the patterns of the hottest period. Women used to bring and wash their children less than 5 years even when the day minimal of air temperature was below $15{ }^{\circ} \mathrm{C}$. Here, the values of the coefficients of determination $\left(\mathrm{R}^{2}\right)$ for the coldest period were lower than those for the hottest period.

\subsubsection{Hot days versus cold days}

Based on results in Fig. 4, we used the daily mean air temperature of $25^{\circ} \mathrm{C}$ as cut-off point to demarcate cold days $\left(<25{ }^{\circ} \mathrm{C}\right)$ from hot days $\left(\geq 25^{\circ} \mathrm{C}\right)$ over a 31-year timeframe (1980-2010) as indicated in Fig. 6. The results indicate that $100 \%$ days were hot in 3 months (April, May and October); $99 \%$ days were hot in 2 months (March and June). Contrastingly, more than $50 \%$ days were cold over 2 months (January and December).

\subsubsection{Short-term influence (hour scale)}

Figure 7a shows the hourly occurrence of swimming. During the coldest period water contacts were recorded in $8 / 12 \mathrm{~h}$ (10 AM to $5 \mathrm{PM}$ ). The total number of contacts was 288 and the highest peak (28\%) occurred at 4 PM. During the hottest period swimming occurred in $10 / 12 \mathrm{~h}$ (8 AM to 5 PM). The total number of contacts was 2405 with the highest peak (21\%) just at 2 PM. 
Fig. 5 Plot of daily air temperatures and frequencies of washing children below 5 years in the river. Graphs $a 1, b 1, c 1$ show situations during the coldest period; graphs $a 2, b 2, c 2$ indicate situations during the hottest period (a1)

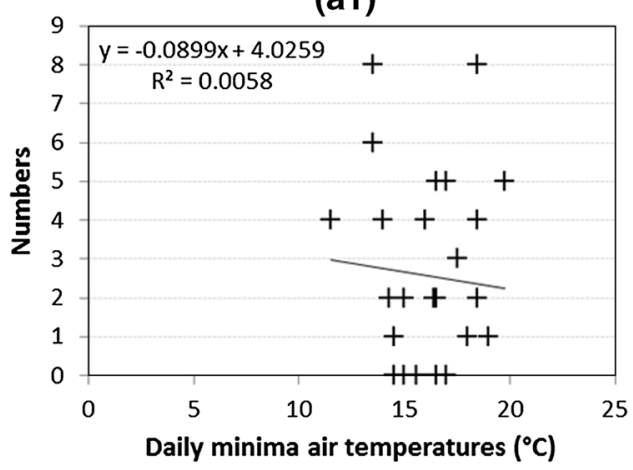

(b1)

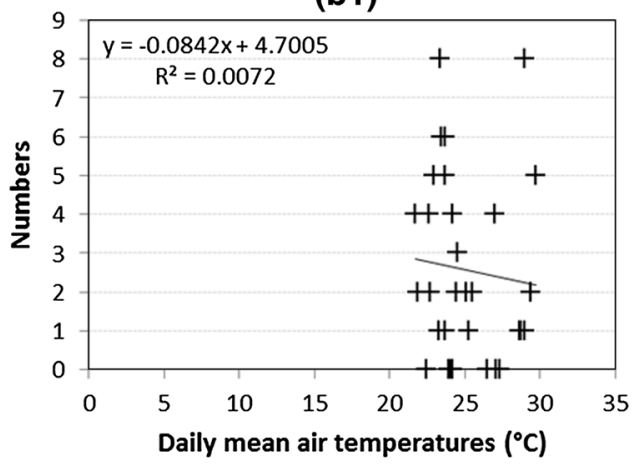

(c1)

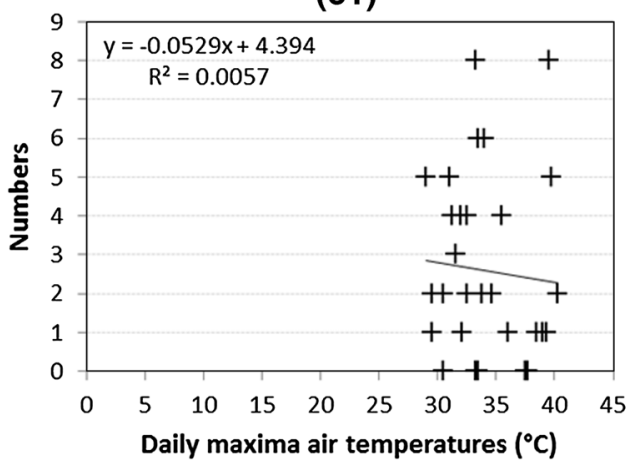

(a2)

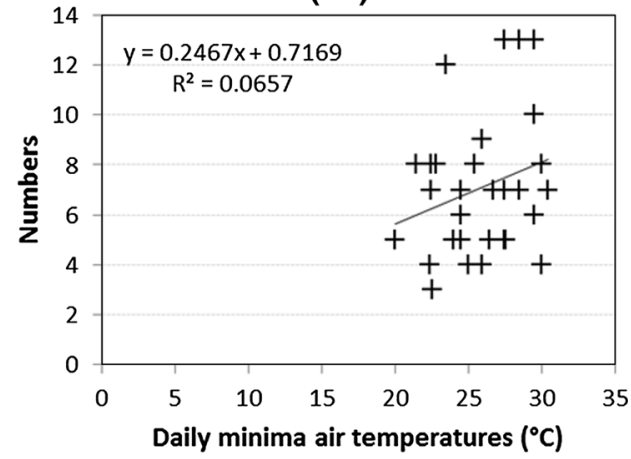

(b2)

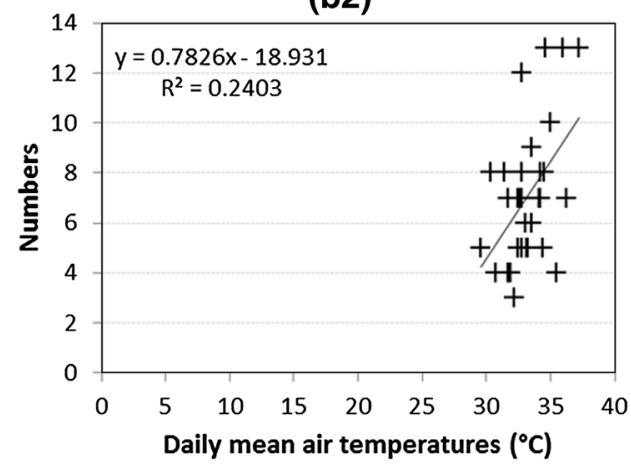

(c2)

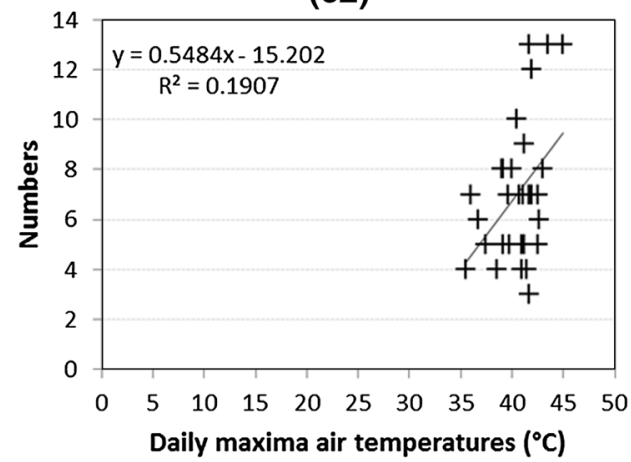

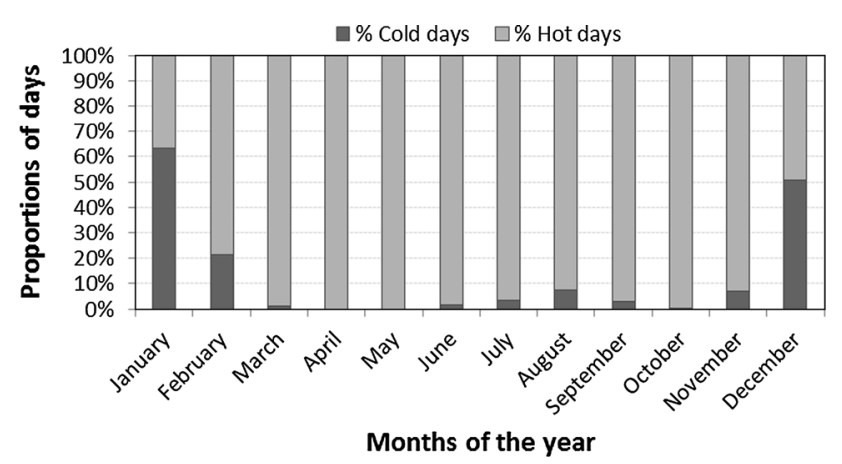

Fig. 6 Distribution $(\%)$ of cold days $\left(<25^{\circ} \mathrm{C}\right)$ and hot days $\left(\geq 25^{\circ} \mathrm{C}\right)$ per month using daily data from 1980 to 2010 (Source of data Di-Sourou weather station)
Figure $7 \mathrm{~b}$ shows that the maximum $(21 \%)$ of the total of 80 water contacts through the bathing of children below the age of 5 years was observed at 6 AM during the coldest period. During the hottest period the peak $(16 \%)$ of the total of 220 contacts was observed at 2 PM.

\section{Discussion}

This study determined through direct field observations the influence of air temperature on children water contact frequencies with respect to human schistosomiasis transmission risk in Toma-Île village which is located in the Sourou Valley, North-western Burkina Faso. 


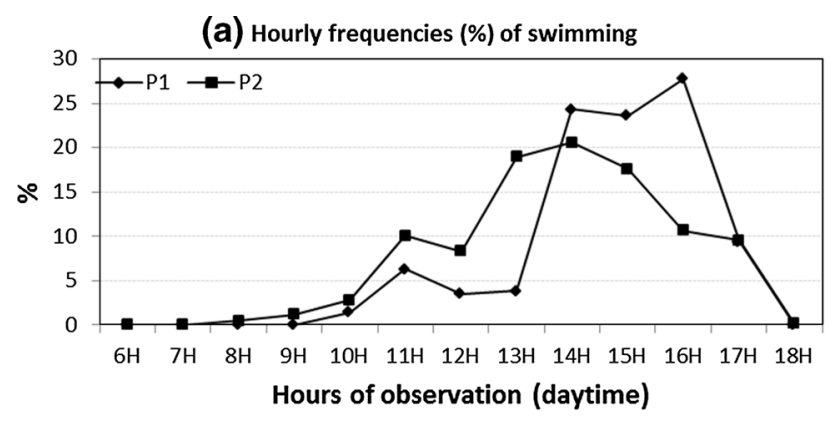

(b) Hourly frequencies (\%) of bathing of children under 5 years

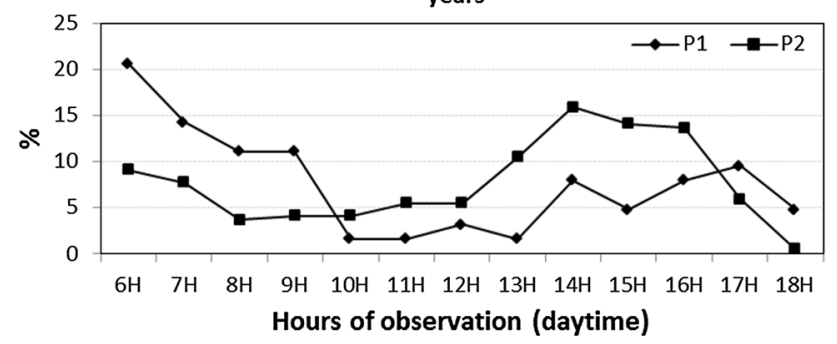

Fig. 7 Profiles of the hourly occurrence of water contacts. $P 1$ Coldest period (3rd January to 2nd February 2011); P2 hottest period (3rd April to 3rd May 2011)

\subsection{Study approach and data collection}

Two approaches were used to measure individual exposure to the risk of transmission of schistosomiasis. The quantitative approach based on direct field observation and the qualitative approach based on individual report of water contacts (Ernould 2000). The first method was used in this study, consisting in tracking contact activities namely swimming and bathing. The link to the risk of schistosomiasis transmission in the context of this study was limited to the contact with the Sourou River standing as an excellent habitat both for Bulinus truncatus, the snail intermediate hosts for S. haematobium, and Biomphalaria pfeifferi, snail intermediate host for $S$. mansoni (Poda et al. 2004; Dianou et al. 2004; Poda et al. 2006; Zongo et al. 2012). Since the schistosomiasis transmission route is the contact with water, any contact with the river is deemed to be risky. The magnitude of the risk is driven by many factors such as the time the contact occurs (morning, noon, afternoon), the duration and the degree of immersion of the body (Takougang et al. 1993; Ernould 2000).

Toma-Île, the site of this study, is a lakeside village totally surrounded by water inhabited by a small community of 40 compounds and 460 inhabitants with slight difference in the socioeconomic status (Traoré 2013). Children ( $<15$ years old) represent about $51 \%$ of the population (INSD 2008). In this study, children were not followed up individually, and since our aim was not to quantify water contacts per child, no additional census was needed. The purpose of the work is to link child behaviour to temperature variability. When coming from outside the village, a canoe is needed to reach the water contact points we observed. Therefore, all children observed in contact with the river were dwelling in the village. This means that the children were observed in their natural environment. Willing to map the urinary schistosomiasis prevalence among schoolchildren in 2011 in the study area, Traoré et al. (2012) realized that no school-goers were coming from Toma-île. Therefore, school holidays did not have any influence on the results of this study. In the context of Toma-Île, swimming or bathing are diurnal activities. Therefore observations were carried out in the daytime, from the sunrise to the sunset. During this time, we recorded all water contacts. The selection of two observation periods of 31 days each enabled to compare swimming or bathing frequencies within and among the observation periods in order to better understand the influence of air temperature on water contact frequencies. Children with different socioeconomic status and residential locations may have different water-contact behaviours (Gazzinelli et al. 2006). In Senegal, Scott et al. (2003) found that that age, sex and place of residence do determine exposure without suggesting that exposure has an influence on the relationship across/between these factors and the intensity of the infection. The socioeconomic status plays a minor role in the case of Toma-Île where the entire community have contacts with the river because of the lack of hydraulic facilities.

\subsection{Influence of air temperature on children behaviour}

The study was designed to catch the role of the heat in triggering swimming or bathing activities. Toma-Île, being a lakeside setting without any safe water supply facilities and where the Sourou River remains the unique water source point, this provides an opportunity to observe such behaviour. The sample scheme targeted children and consisted in recording all entries into the river for swimming or bathing on a daily basis. Even though the perception of heat is different among individuals, extreme heat typically leads to avoidance mechanisms. For children in the Sourou Valley, swimming comes out as a reaction to hot days. In the context of our study, hot days leading to swimming were characterized by daily mean temperatures of $25^{\circ} \mathrm{C}$ and more. The first 20 days of observation could be categorized as cold days. Consequently, children did not go swimming in the river. Hot days totalled the remaining 42/62 days of observation and children generally reacted by swimming, not continuously though. The number of daily water contacts varied unevenly during these 42 hot days. This fact explains the lower values of $\mathrm{R}^{2}$ obtained 
during the hottest period (Fig. 4). Chandiwana (1987) observed seasonal variation of water contacts with intense contacts during the hot dry season in Zimbabwe. The author considered swimming activities as 'pressures' since with every individual swimming increased the chance of introducing parasites into the river. On an annual scale, considerable pressures on the river due to swimming were recorded in 5 months (March, April, May, June and October) since children went swimming every day. Lower pressures on the river were observed during 3 months (January, February and December) because children did not go swimming every day. However, whatever the period and temperature, children never went swimming during the entire daytime. Peaks of recreational swimming were observed by Watts et al. (1998) in summer. The hourly occurrence of swimming showed a shift of $2 \mathrm{~h}$ between the coldest period and the hottest one. Children started to play in the river from $10 \mathrm{AM}$ during the cold period while, as compared to an earlier starting time during the hot period, around $8 \mathrm{AM}$. The same lag could be observed for peaks of swimming times: 4 PM versus 2 PM, respectively (Fig. 7a). Higher air temperatures led to higher swimming frequencies, earlier starts and a later end of the swimming period. The total absence of clean water facilities explains why women wash children less than 5 years old directly in the river. Peaks of bathing observed at 6 AM can be explained by the fact that during the night, children below the age of 5 years often defecate. Therefore, daily bathing is carried out in the morning, irrespective of temperatures. This explains why values of $\mathrm{R}^{2}$ for temperature and bathing were very low (Fig. 5). The influence of air temperature appeared more clearly at the hourly level. The curve representing the frequencies of bathing during the hottest period is above that of the coldest period from $10 \mathrm{AM}$ to 4 PM (Fig. 7b). Similar results were found by Takougang et al. (1993) in the extreme North of Cameroon and by Zongo et al. (2012) over 10 sites in Burkina Faso.

At the Di-Sourou weather station hourly data are not measured. Temperatures are recorded three times a day: 6 AM, 12 and 17 PM. Therefore, local data about daily minimum and maximum air temperatures were missing. Since all curves representing hourly frequencies of swimming and bathing showed a peak at 2 PM (Fig. 7), we assumed this time to be the hottest in the daytime.

\subsection{Schistosomiasis transmission risk}

Our field observation was not coupled with parasitological examinations of urines and faeces to check the relations between water contact and infection. However, such relationship derived from empirical studies. Tay et al. (2011) found a significant association between specific water contacts including bathing and playing in streams/ponds in
Ghana. Kloos et al. (1990) indicated overall significant correlations between water contacts and schistosomiasis infection. But swimming was the only activity positively correlated with egg-counts, all other activities being negatively correlated. Swimming leads to exposing the whole body, which increases the risk of infection (Takougang et al 1993). This water contact occurs at the time when cercariae are very active with increase of infectivity (Stirewalt 1954; N'Goran et al. 1997). The duration of the exposure to contaminated water can increase the risk of infection since several cercariae can penetrate the swimmer's body. The intensity of penetration will also depend on the density of the cercariae at the contact point (Ernould 2000).

Swimming or bathing is a key cause of schistosomiasis transmission in the water points inhabited by snail species which are the intermediate hosts of the parasite. S. mansoni and $S$. haematobium cercariae are usually released from their intermediate hosts during the daytime; they showed mean shedding time between 1 PM and 4 PM (Nojima and Sato 1982; Théron 1984; N'Goran et al. 1997; Wolmarans et al. 2002). The daily peak of human pressure of water exposure was observed at the hottest hours of the daytime (1 PM and 3 PM). Although many parameters govern cercarial shedding, rhythms of cercarial emergence have been found as adaptive behaviours and shaped under the selective pressures exerted by the behaviour of the human host. The early or late cercarial emergence pattern is influenced by the epidemiological predominance of the human host in the transmission zone (Théron 1984). Numerous studies found that the circadian cercarial shedding shows low intensities to null shedding before 9 AM and after 5 PM, and high intensity around noon (Théron 1984; N'Goran et al. 1997; Wolmarans et al. 2002). According to our observations (Fig. 7), there is a coincidence of higher density of children with a higher density of infecting cercariae in the same water between $1 \mathrm{PM}$ and 4 PM. Subsequently, there is increasing likelihood to encounter the cercariae. Contrastingly, bathing occurring at $6 \mathrm{AM}$ is associated with lesser likelihood; hence a lower risk. Since, the exposure risk is function of the presence of cercariae in the water, low cercarial shedding periods can be qualify as periods of low risk.

Water contact per se is not a direct measure of exposure. Many aspects of contact (such as the frequency or total duration of contact, the proportion of the body being exposed and the moment of the occurrence) contribute to the likelihood of encountering infective cercariae. However, air temperature appears to be a good proxy indicator in terms of temporal variation of schistosomiasis transmission risks. Nevertheless, the key drivers may include several other socioeconomic factors (Chandiwana 1987; Takougang et al. 1993; Amazigo et al. 1997; Kloos et al. 
1998; Watts et al. 1998; Ernould 2000; Scott et al. 2003; Grisorio et al. 2005).

Swimming or bathing may also lead to the contamination of waterbodies. The circadian rhythm of schistosome eggs excretion in the urine was reported from various geographical areas in Egypt, in East and West Africa and even out of African (McMahon 1976; Doehring et al. 1985). Traoré (2013) reported urination of children during swimming in Toma-Île. Infected children may deposit eggs contained in urine directly in the water. Fragments of faeces on the bodies of young children may also contain eggs. Bathing directly in the river may bring about the contamination of water.

\subsection{Potential impact of climate variability and climate change on schistosomiasis transmission in the Sourou Valley}

There is evidence of the impact of climate variability and climate change on the three actors (parasite-snail intermediate host-human-being) of the schistosomiasis development cycle in literature (Mangal et al. 2008; Zhou et al. 2008; Tay et al. 2011). Our findings show that increase in air temperature leads to massive swimming or bathing. An increase in the mean air temperature of $0.8{ }^{\circ} \mathrm{C}$ by 2025 and of $1.7{ }^{\circ} \mathrm{C}$ by 2050 is forecasted at the country scale by the Program of national action of adaptation to the variability and to climate change (PANA 2007). Such a rise in temperature will affect the monthly distribution of the proportions of cold and hot days (Fig. 6). Breaks of water contacts observed during the coldest period will became shorter since the number of hot days will dramatically increase. Exposure to schistosomiasis through swimming or bathing will occur more frequently and continually.

\subsection{Health policy implications to reduce schistosomiasis risk based on our findings}

Based on our findings, the safe water and adequate sanitation supply constitutes a health policy implication on how to reduce schistosomiasis. A major strategy for the resilience to climate change and the control of schistosomiasis will be the supply of safe water for children recreational activities. While the politically agenda prioritising drinking and cooking water (DGRE 2006), safe water for ludic activities should be included in national programs to enhance the water supply and sanitation services. Several studies reported that an excellent water and sanitation supply can break the transmission cycle (White et al. 1972; Esrey et al. 1990). But to be effective in controlling human schistosomiasis, water supply and sanitation must be convenient enough to successfully discourage water activities in contaminated water (Cairncross and Valdmanis 2006).
Water and sanitation supply should be accompanied by massive drug administration campaigns with praziquantel at least ones per year particularly in lakeside settlements like Toma-Île.

\section{Conclusion}

This study determined for the first time the threshold of air temperature at which children have the sensation of heat and react by swimming in contaminated water. In their desire to fight against extreme heat, children look for freshwater as a means for natural cooling and, by so doing, expose themselves to the risk of the transmission of schistosomiasis. Despite the relative short period (62 days) of direct field observation, the results showed a strong influence of air temperature on children's recreational swimming temporal patterns. We suggest that future research should undertake a long-term observation (at least 1 year) in order to confirm or refute the threshold of daily mean air temperature of $25^{\circ} \mathrm{C}$ we found to be the starting point of children's exposure to contaminated water through swimming and increases in bathing frequency. Our findings indicate that information on the temporal variation in water contact and schistosomiasis transmission can be useful in strategies to reduce transmission by regulating swimming or bathing during high risk periods, possibly by limiting access to the river at such times. The figures provided in the paper may be used to inform models of transmission and optimise control programmes, especially while delivering mass drug administration programmes just after hot seasons.

In the way forwards, an integration of environmental data and information on human behaviour can be valuable in designing and improving models of vector-borne disease transmission. Such models are increasingly used to predict disease outbreaks of high or emerging public health relevance (Aldstadt 2007; Hollingsworth et al. 2014) such as malaria (Hoshen and Morse 2004) and dengue fever (Liao et al. 2014; Yu et al. 2011).

Acknowledgments We thank the children, parents and the communities of Toma-Île for their support and willingness to participate in this study. We also thank fieldworkers who undertook the survey.

\section{Compliance with ethical standards}

Conflict of Interest The authors declare that they have no conflict of interest.

Open Access This article is distributed under the terms of the Creative Commons Attribution 4.0 International License (http://crea tivecommons.org/licenses/by/4.0/), which permits unrestricted use, distribution, and reproduction in any medium, provided you give appropriate credit to the original author(s) and the source, provide a link to the Creative Commons license, and indicate if changes were made. 


\section{References}

Aldstadt J (2007) An incremental Knox test for the determination of the serial interval between successive cases of an infectious disease. Stoch Environ Res Risk A 21(5):487-500

Amazigo UO, Anago-Amanze CI, Okeibunor JC (1997) Urinary schistosomiasis among school children in Nigeria: consequences of indigenous beliefs and water contact activities. J Biosoc Sci 29:9-18

Butterworth AE, Hagan P (1987) Immunity in human schistosomiasis. Parasitol Today 3(1):11-16

Cairncross S, Valdmanis V (2006) Water supply, sanitation, and hygiene promotion. In: Janison DT, Breman JG, Measham AR (eds) Disease control priorities in developing countries, 2nd edn. World Bank, Washington, DC, pp 771-792

Chu KY, Massoud J, Sabbaghian H (1966) Host-parasite relationship of Bulinus truncates and Schistosoma haematobium in Iran. 3. Effect of water temperature on the ability of miracidia to infect snails. Bull World Health Organ 34:131-133

Clements ACA, Garba A, Sacko M, Toure S, Dembele R, Landoure A, Bosque-Oliva E, Gabrielli AF, Fenwick A (2008) Mapping the probability of schistosomiasis and associated uncertainty, West Africa. Emerg Infect Dis 14(10):1629-1632

DeWitt WB (1955) Influence of temperature on penetration of snail hosts by Schistosoma mansoni miracidia. Exp Parasitol 4(3):271-276

DGRE (2006) Programme National d'Approvisionnement en Eau Potable et d'Assainissement à l'horizon 2015-PN-AEPA 2015. Direction Générale des Ressources en Eau (DGRE), Ouagadougou

Dianou D, Poda JN, Savadogo LG, Sorgho H, Wango SP, Sondo B (2004) Parasitoses intestinales dans la zone du complex hydroagricole du Sourou au Burkina Faso. VertigO 5(2):8p

Doehring E, Vester U, Ehrich HHJ, Feldmeier H (1985) Circadian variation of ova excretion, proteinuria, hematuria, and leukocyturia in urinary schistosomiasis. Kidney Int 27:667-671

Ernould JC (2000) Importance du comportement humain dans la transmission des Schistosomoses. In: Chippaux JP (ed) La lutte contre les schistosomoses en Afrique de l'Ouest. Colloques et Séminaires, éditions IRD, pp 43-46

Esrey SA, Potash JB, Roberts L, Shiff C (1990) Health benefits from improvements in water supply and sanitation: survey and analysis of the literature on selected diseases. WASH technical Report no. 66. United States Agency for International Development, Washington, DC

Ficetola GF, Denoël M (2009) Ecological thresholds: an assessment of methods to identify abrupt changes in species-habitat relationships. Ecography 32(6):1075-1084. doi:10.1111/j.16000587.2009.05571.x

Fulford AJC, Webster M, Ouma JH, Kimani G, Dunne DW (1998) Puberty and age-related changes in susceptibility to schistosome infection. Parasitol Today 14(1):23-26

Gazzinelli A, Velasquez-Melendez G, Crawford SB, LoVerde PT, Correa-Oliveira R, Kloos H (2006) Socioeconomic determinants of schistosomiasis in a poor rural area in Brazil. Running short title: Socioeconomic determinants of schistosomiasis in Brazil. Acta Trop 99(2-3):260-271

Grisorio E, Bremond P, Mietton M (2005) Les différentes dimensions dun risque à linterface environnement-santé. Approche écogéographique dune maladie hydro-dépendante: La schistosomose urogénitale à Madagascar. Environ Risques Santé 4(5):335-340

Gryseels B, Nkulikyinka L (1990) The Morbidity of Schistosomiasis mansoni in the Highland focus of Lake Cohoha, Burundi. Trans R Soc Trop Med Hyg 84:542-547

Gryseels B, Polman K, Clerinx J, Kestens L (2006) Human Schistosomiasis. The Lancet 368(9541):1106-1118
Hollingsworth TD, Pulliam JRC, Funk S, Truscott JE, Ishami V, Lloyd AL (2014) Seven challenges for modelling indirect transmission: vector-borne diseases, macroparasites and neglected tropical diseases. Epidemics. doi:10.1016/j.epidem.2014.08.007

Hoshen MB, Morse AP (2004) A weather-driven model of malaria transmission. Malar J 3:32. doi:10.1186/1475-2875-3-32

Hotez PJ, Kamath A (2009) Neglected tropical diseases in SubSaharan Africa: review of their prevalence, distribution, and disease burden. PLoS Negl Trop Dis 3(8):e412

INSD (2008) Recensement général de la population et de l'habitation de 2006. Résultats définitifs. Institut National de la Statistique et de la Démographie (INSD), Ouagadougou

Kabatereine NB, Vennervald BJ, Ouma JH, Kemijumbi J, Butterworth AE, Dunne DW, Fulford AJC (1999) Adult resistance to schistosomiasis mansoni: age dependence of reinfection remains constant in communities with diverse exposure patterns. Parasitology 118:101-105

Karthe D (2010) Geographic determinants of malaria transmission. A case study from Kossi Province, Burkina Faso. Ph.D. dissertation, University of Göttingen, Germany. http://webdoc.sub. gwdg.de/diss/2010/karthe/karthe.pdf

Karthe D, Traoré I (2009) Geographic pattern of malaria transmission: a case study from Kossi Province, Burkina Faso. Geoöko 30(1-2):43-63

Karthe D, Traoré I, Reeh T, Ouédraogo F, Pörtge KH (2011) Das Bewässerungsprojekt im Sourou-Tal/Burkina Faso-eine nachhaltige Maßnahme zur Ernährungssicherung? Zentralblatt für Geologie und Paläontologie 1(1-2):15-37

Karthe D, Traoré I, Sié A, Kappas M (2012) Malaria in Kossi Province, Burkina Faso: an investigation of spatio-temporal incidence pattern. In: Kappas M, Gross U, Kelleher D (eds) Global health: a challenge for interdisciplinary research. Universitätsverlag Göttingen, Göttingen, pp 305-320

King CH, Dangerfield-Cha M (2008) The unacknowledged impact of chronic schistosomiasis. Chronic Illn 4:65-79

Kloos H, Higashi IG, Schinski VD, Mansour NS, Murrell KD, Miller FD (1990) Water contact and Schistosoma haematobium infection: a case study from an upper Egyptian village. Int $\mathrm{J}$ Epidemiol 19(3):749-758

Kloos H, Gazzinelli A, Van Zuyle P (1998) Microgeographical patterns of schistosomiasis and water contact behavior; examples from Africa and Brazil. Mem Inst Oswaldo Cruz, Rio de Janeiro 93(I):37-50

Koukounari A, Gabrielli AF, Toure S, Bosque-Oliva E, Zhang Y, Sellin B, Donnelly CA, Fenwick A, Webster JP (2007) Schistosoma haematobium infection and morbidity before and after large-scale administration of Praziquantel in Burkina Faso. J Infect Dis 196:659-669

Koukounari A, Toure S, Donnelly CA, Ouedraogo A, Yoda B, Ky C, Kaboré M, Bosqué-Oliva E, Basáñez MG, Fenwick A, Webster JP (2011) Integrated monitoring and evaluation and environmental risk factors for urogenital schistosomiasis and active trachoma in Burkina Faso before preventative chemotherapy using sentinel sites. BMC Infect Dis 11(191):12

Liao C-M, Huang T-L, Lin Y-J, You S-H, Cheng Y-H, Hsieh NH, Chen W-Y (2014) Regional response of dengue fever epidemics to interannual variation and related climate variability. Stoch Environ Res Risk A 29(3):947-958

Mangal TD, Paterson S, Fenton A (2008) Predicting the impact of long-term temperature changes on the epidemiology and control of schistosomiasis: a mechanistic model. PLoS One 3(1):e1438. doi:10.1371/journal.pone.0001438

Mayer JD (1983) The role of spatial analysis and geographic data in the detection of disease causation. Soc Sci Med 17(16):1213-1221 
McMahon JE (1976) Circadian rhythm in Schistosoma haematobium egg excretion. Int J Parasitol 6:373-377

N'Goran E, Bremond P, Sellin E, Sellin B, Theron A (1997) Intraspecific diversity of Schistosoma haematobium in West Africa: chronobiology of cercarial emergence. Acta Trop 66:35-44

Nojima H, Sato A (1982) Schistosoma mansoni and Schistosoma haematobium: emergence of schistosome cercariae from snails with darkness and illumination. Exp Parasitol 53(2):189-198

PANA (2007) Programme d'action national d'adaptation à la variabilité et aux changements climatiques (PANA du Burkina Faso). Secrétariat Permanent du Conseil National pour l'Environnement et le Développement Durable/Ministère de 1'Environnement et du Cadre de Vie/ Burkina Faso

Poda JN, Wango SP, Sorgho R, Dianou D (2004) Evolution récente des schistosomoses dans le complexe hydroagricole du Sourou au Burkina Faso. Bull Soc Pathol Exot 97(1):15-18

Poda JN, Mwanga J, Dianou D, Garba A, Ouedraogo FC, Zongo D, Sondo KB (2006) Les parasitoses qui minent les nouveaux pôles de développement au Burkina Faso : cas des schistosomoses et des géohelminthes dans le complexe hydroagricole du Sourou. VertigO 7(2):1-7

Scott JT, Diakhate M, Vereecken K, Fall A, Diop M, Ly A, De Clercq D, de Vlas SJ, Berkvens D, Kestens L, Gryseels B (2003) Human water contacts patterns in Schistosoma mansoni epidemic foci in northern Senegal change according to age, sex and place of residence, but are not related to intensity of infection. Trop Med Int Health 8(2):100-108

Sk Chandiwana (1987) Community water-contact patterns and the transmission of schistosoma haematobium in the highveld region of Zimbabwe. Soc Sci Med 25(5):495-505

Steinmann P, Keiser J, Bos R, Tanner M, Utzinger J (2006) Schistosomiasis and water resources development: systematic review, meta-analysis, and estimates of people at risk. The Lancet 6(7):411-425

Stirewalt MA (1954) Effect of snail maintenance temperatures on development of Schistosoma mansoni. Exp Parasitol 3(6):504-516

Takougang I, Louis JP, Migliani R, Noumi E, Mohome N, Ekobo AS (1993) Quelques aspects comportementaux de ĺexposition à la bilharziose dans les aménagements hydroagricoles en zone sahélienne (extrême nord du Cameroun). Cahier Santé 3:457-463

Tay SCK, Amekudzi LK, Tagoe G (2011) Comparative study of the impact of climate variability on prevalence of urinary schistosomiasis: cases at Sunyani Regional Hospital and among School Children in Atronie, Sunyani. J Environ Sci Eng 5:1474-1482

Théron A (1984) Early and late shedding patterns of Schistosomiasis mansoni Cercariae: ecological significance in transmission to human and murine hosts. J Parasitol 70(5):652-655
Traoré I (2013) Geographic determinants of human schistosomiasis transmission in the Sourou Valley, Burkina Faso. Ph.D. dissertation, University of Göttingen, Germany. http://hdl.handle.net/ 11858/00-1735-0000-0001-BB25-F

Traoré I, Ouédraogo FC, Yé M, Sié A, Karthe D (2011) Distribution spatiale de la mortalité palustre dans le district sanitaire de Nouna au nord-ouest du Burkina Faso. J African des Sci de l'Environnement 1:27-49

Traoré I, Sié A, Coulibaly B, Yé M, Karthe D, Kappas M (2012) Rapid screening and mapping of urinary schistosomiasis prevalence among primary school children in Sourou Valley, Burkina Faso. In: Kappas M, Gross U, Kelleher D (eds) Global health: a challenge for interdisciplinary research. Universitätsverlag Göttingen, Göttingen, pp 255-281

Utzinger J, Raso G, Brooker S, De Savigny D, Tanner M, Ørnbjerg N, Singer BH, N'Goran EK (2009) Schistosomiasis and neglected tropical diseases: towards integrated and sustainable control and a word of caution. Parasitology 136:1859-1874

Van der Werf MJ, de Vlas SJ, Brooker S, Looman CWN, Nagelkerke NJD, Habbema JDF, Engels D (2003) Quantification of clinical morbidity associated with schistosome infection in sub-Saharan Africa. Acta Trop 86:125-139

Watts S, Khallaayoune K, Bensefia R, Laamrani H, Gryseels B (1998) The study of human behavior and Schistosomiasis transmission in an irrigated Area in morocco. Soc Sci Med 46(6):755-765

Weil C, Kvale KM (1985) Current research on geographical aspects of schistosomiasis. Geogr Rev 75(2):186-216

White GF, Bradley DJ, White AU (1972) Drawers of water. Domestic water use in East Africa. University of Chicago Press; reproduced by Bulletin of the WHO, 2002, 80(1): 63-73

WHO (2013) Sustaining the drive to overcome the global impact of neglected tropical diseases: second WHO report on neglected tropical diseases. WHO/HTM/NTD/2013.1

Wolmarans CT, de Kock KN, Strauss HD, Bornman M (2002) Daily emergence of Schistosoma mansoni and S. haematobium cercariae from naturally infected snails under field conditions. J Helminthol 76:273-277

Yu H-L, Yang S-J, Yen H-J, Christakos G (2011) A spatio-temporal climate-based model of early dengue fever warning in southern Taiwan. Stoch Environ Res Risk A 25(4):485-494

Zhou XN, Yang GJ, Yang K, Wang X-H, Hong Q-B, Sun L-P, Malone JB, Kristensen TK, Bergquist NR, Utzinger J (2008) Potential impact of climate change on schistosomiasis transmission in China. Am J Trop Med Hyg 78(2):188-194

Zongo D, Kabre BG, Dayeri D, Savadogo B, Poda JN (2012) Étude comparative de la transmission de la schistosomiase (formes urinaire et intestinale) dans dix sites du Burkina Faso. Médecine et Santé Tropicales 22:323-329 